\title{
Behavior at the Local Level
}

\author{
Neelanjan Sircar (Columbia University \& University of Pennsylvania) \\ Ty Turley (Brigham Young University) \\ Maarten Voors (Cambridge University \& Wageningen University)* \\ Peter van der Windt (Columbia University \& Wageningen University)
}

April 26, 2014

\begin{abstract}
Laboratory experiments have become a popular tool to learn about preferences and behavior. Classic laboratory games ordinarily have two characteristics. First, the players are anonymous, and second, they are strangers. This study subverts these characteristics to explore behavior when subjects play against identified members of their own social network. We play an ultimatum game in highly connected, rural villages in Sierra Leone. We randomly assign players to either the classic game or a modified game with revealed identity and compare behavior across these variations. We find that classic games do not translate well to behavior in the local context. Revealing the identity of the receiver leads to an increase in offers, supporting the idea that people care about revealed attributes, and that their average belief about one's personal reputation exceeds the average belief about the reputation of the status quo. Variation in sizes of offers made increases in the version of the game with the most information revealed as would be expected if social relationships can be both good and bad.
\end{abstract}

\footnotetext{
${ }^{*}$ Corresponding author: maarten.voors@wur.nl. We are indebted to the Gola Rainforest National Park and its partners (Government of Sierra Leone, Conservation Society of Sierra Leone and the Royal Society for the Protection of Birds), supported by the European Union and the Fonds Français pour l'Environnement Mondial. We thank Paul Richards, Erwin Bulte and Andreas Kontoleon for their collaboration. We thank N.W.O. grant \# 453-10-001, ESRC and Cambridge University's CCI for financial support. Thanks also to Esther Mokuwa, Koen Leuveld and our team of local enumerators for exceptional research assistance in Sierra Leone.
} 


\section{Introduction}

Unlike developed countries, where exchange often occurs through impersonal interactions, a large literature on the political economy of development finds that local characteristics such as reciprocity and network structure are much more likely to govern behavior in developing countries (e.g. Udry (1994) and Fafchamps and Lund (2003)). In this paper we explore the effect of adding local context to an ultimatum game among a socially connected subject pool.

Experimental games are often used to make sophisticated inferences about underlying behaviors and preferences. Several types of games have been proposed, the dictator game to learn about altruistic preferences, ultimatum games to learn about preferences for fairness, public goods games to learn about cooperative behavior, among others. These experimental games ordinarily have two characteristics. First, players do not know anything about their counterparts except for that which is revealed by the experimenter. Second, players do not know each other personally. The original protocol for the dictator game, for example, entailed informing the dictator that the receiver was behind a closed door to ensure anonymity. No attributes of the receiver could affect the decision of the dictator (e.g. Kahneman et al. (1986)).

In this paper we will refer to such games as "classic games". This study conjectures that classic games may not relate well to a local setting since it fails to account for how a player's behavior changes based on knowledge of her counterpart's attributes, the previous interactions between these individuals, and the social networks in which both players are embedded (Levitt and List (2007)). Building on a well-developed literature in economics and psychology, we put forth three factors that influence interactions at the local level but that are suppressed in the classic game: reciprocity, knowledge of personal attributes, and quality of social connections.

This study embeds the classic ultimatum game in a local context with two simple adjustments. We reveal the identity of the players in the game and we play with subjects who know each other well. The study uses subjects from small, rural villages in Sierra Leone, where the players know each other well. We allocate 632 players to four different conditions that vary the information players have about the identity of their counterpart. In one condition, both the sender and the receiver are anonymous (the classic game). The other three conditions introduce various degrees of local context into the classic game, including a version where sender and receiver are both fully identified to each other (the strongest use of local context possible). The classic ultimatum game has typically been used to understand public norms of fairness. By revealing the identity of sender, receiver, or both, we are able to analyze private norms of fairness; that is, we are able to analyze 
how norms of fairness vary due to personal reputations and interpersonal relations.

We believe this study tests a fundamental question concerning the use of classic experimental methods to study human behavior across settings. While lab experiments may abstract from social dimensions of human behavior to estimate underlying preferences, this abstraction ignores the social dimension of behavior that could easily swamp the importance of personal preferences in highly socially connected societies. We find that revealing the identity of the receiver leads to an increase in contributions, supporting the idea that people care about revealed attributes, and their social connections. In particular, this demonstrates that individuals believe that the average person believes that her personal reputation exceeds that of the status quo and that interpersonal relations are generally positive. We also find that senders do not respond to knowing that receivers will know them, meaning that the average perception of fairness of other individuals is consistent with the status quo. Variation in sizes of offers made increases in the version of the game with the most information revealed as would be expected if behavior in the game is conditioned upon existing, positive or negative, interpersonal relations.

The next section explains the three factors that we argue differentiate behavior at the local level. Section 3 introduces the Sierra Leonean context and our experimental design. Section 4 presents results, and discusses possible explanations for those results. We conclude in Section 5 ,

\section{Measuring Behavior at the Local Level}

Laboratory style experiments have become a popular tool to learn about human preferences and behavior. A substantial body of literature has focused on social preferences, investigating differences in trust, reciprocity, fairness, altruism and the propensity to cooperate (Camerer, 2003). One of the workhorse laboratory experiments to understand fairness norms is the ultimatum game, first studied in Guth et al. (1982) (see Roth (1995) for more information). The game takes a single player (the sender) and asks her to split a fixed sum of money (the endowment) between herself and another person (the receiver). The receiver subsequently decides to accept or reject the offer. If the offer is accepted, both players receive the allocation as suggested. If rejected, both players receive nothing. In the classic version of this game the players do not know anything about their opponent in the game and they do not know their counterpart outside the game. Table 1 presents an overview of the 10 most cited (from left to right) ultimatum game studies in any economics journal 1

\footnotetext{
${ }^{1}$ Search term in Googlescholar "ultimatum game". Accessed: February 22, 2014. (Thaler, 1988, Oosterbeek et al. 2004) are among the most highly cited studies, but are meta studies and do not conduct an original ultimatum game experiment.
} 
These studies show that behaviors related to fairness depend on a multitude of factors: for example, those related to player characteristics (such as their physical attractiveness and gender) and the context of interaction (such as the stakes involved in the game, e.g., Cameron (1999) ). In eight of the ten studies both the sender and receiver play anonymously and subjects do not know each other personally; they typically are university students. One exception is Solnick and Schweitzer (1999) who reveal (via a photo) the identity of the receiver and the sender to learn about the influence of physical attractiveness on the bargaining process. The researchers, though, explicitly recruited two nonoverlapping samples from different universities to ensure that players did not know each other. In Charness and Gneezy (2008) participants know the family name of their counterparts, but the authors are careful to note that "Participants from two different universities are used to ensure that this is the only additional information they receive (that is, they do not know their counterparts personally). (p.30)".

\begin{tabular}{|c|c|c|c|c|c|c|}
\hline Study: & Type & Location & Sender & Receiver & Sample & Participants \\
\hline This study & UG & LF & $\mathrm{R}$ & $\mathrm{R}$ & K & Rural villagers in Sierra Leone \\
\hline Gale et al. 1995$)$ & $\mathrm{UG}$ & $\mathrm{L}$ & $\mathrm{A}$ & $\mathrm{A}$ & $\mathrm{U}$ & Dont know \\
\hline Cameron (1999) & UG & $\mathrm{L}$ & A & A & $\mathrm{U}$ & Sociology and politics students in Indonesia \\
\hline Hoffman et al. (1996) & $\mathrm{UG}$ & $\mathrm{L}$ & A & A & $\mathrm{U}$ & Subjects recruited via University of Arizona \\
\hline Kagel et al. (1996) & $\mathrm{UG}$ & $\mathrm{L}$ & A & A & $\mathrm{U}$ & Economics and psychology undergraduates \\
\hline Ruffle $(1998)$ & $\mathrm{UG}$ & $\mathrm{L}$ & A & A & $\mathrm{U}$ & Subjects at Princeton University \\
\hline Solnick and Schweitzer 1999$)$ & $\mathrm{UG}$ & $\mathrm{L}$ & $\mathrm{R}$ & $\mathrm{R}$ & $\mathrm{U}$ & Students from two different universities \\
\hline Bornstein and Yaniv (1998) & $\mathrm{UG}$ & $\mathrm{L}$ & $\mathrm{A}$ & A & $\mathrm{U}$ & Male students \\
\hline Güth et al. (2001) & $\mathrm{UG}$ & $\mathrm{L}$ & $\mathrm{A}$ & A & $\mathrm{U}$ & Undergraduates from Humbolt University \\
\hline Charness and Gneezy (2008) & $\mathrm{UG}$ & $\mathrm{L}$ & $\mathrm{R}$ & $\mathrm{A}$ & $\mathrm{U}$ & Participants from two different universities \\
\hline Solnick $(2001)$ & $\mathrm{UG}$ & $\mathrm{L}$ & $\mathrm{A}$ & A & $\mathrm{U}$ & University of Pennsylvania students \\
\hline
\end{tabular}

Table 1: Overview Local Context in Ultimatum Games. Under 'Type', "UG", "T" and "D" indicate ultimatum, trust and dictator games, respectively. Under 'Location', "L" indicates laboratory games, whereas "LF" are lab-in-the-field experiments. Under 'Sender' and 'Receiver', "A" ("R") indicates whether the player is anonymous (revealed) towards the other player. Finally, the row 'Sample' indicates if the players are known to each other ("K"), or not ("U").

There are compelling reasons to use anonymity in lab settings. It allows researchers to isolate underlying behavioral preferences without contamination by social considerations. It abstracts from something (the social relationships between participants) that the experimenter cannot exogenously manipulate. To get cleaner identification of a social preference it is helpful to eliminate this confound. We argue that it is important to include (local) context in lab games as it allows for a better extrapolation of lab experimental results into real-world behavior. For example, isolating non-social preferences would lead to biased estimates of how these preferences would ever be expressed in actuality. For many societies, and in particular for individuals in developing countries, much of economic life is organized 
in social groups and settings.

Levitt and List (2007) propose that such divergence is influenced by not only monetary calculations but also by several other factors including (i) the stakes of the game (ii) the presence of moral and ethical considerations, (iii) the extent to which one's actions are scrutinized by others and the nature of such scrutiny, (iv) the subject pool of respondents and ( $\mathrm{v}$ ) the context in which the decision is embedded. In this study we focus on the context in particular. In many developing country settings, where the reach of formal government is limited, local norms and rules of conduct are essential for the provision of public goods and the regulation of common pool resources. Understanding differences in social behavior is important as social factors are the key drivers of poverty, growth and development. We argue there are four factors that may cause game behavior to differ when embedded in a local setting:

1. Reciprocation In a local setting individuals interact repeatedly with each other, and these individuals are identifiable. As a result, current behavior is dependent on past interactions and expected future interaction. A well-developed literature documents the importance of reciprocity-both positive and negative-in individual behavior (e.g. Trivers (1971), Bowles and Gintis (2004)). Even in the absence of repeated encounters between the same individuals, reciprocity influences behavior due to reputational considerations (e.g. Leimar and Hammerstein (2001)). Factors related to reciprocity are excluded from the classic game.

2. Knowledge of Attributes In the classic game subjects do not have close social ties. The interpretation of any empirical results from such a game are limited to describing the interaction between random strangers with no, or very limited, information about the receivers attributes. In local settings, behavior is based on full information about relevant attributes of the receiver. Indeed, attributes of others, such as ethnicity and gender, has an important influence on behavior (Holm (2000), Habyarimana et al. (2007)).

3. Social Networks At the local level, individuals share a common social context e.g. the village - and are able to place other individuals within the social network. Social relations outside the dyad, such as common friends and knowledge about how this opponent has treated common friends, influence behavior either by mitigating or exuberating biases. There is an increasing literature that analyzes the role of other individuals in the shared social network of a particular dyad, which is known as dyadic interdependence Jackson (2008)). Classic games force the dictator to make determinations about a receiver in the absence of this social context. 2

\footnotetext{
${ }^{2}$ Behavior towards individuals often stands at odds with behavior towards a group (e.g. Hamilton and Sherman (1996)). A related and prominent research agenda studies the "identified victim effect", which is that individuals behave more generously towards identified victims than towards unidentified or 'statistical' victims (Jenni and Lowenstein (1997)). Small (2003) and Kogut and Ritov (2005) show the importance
} 
In this study, we are interested in behavior at the local level conducted with individuals that know each other well and have regular interaction.

\begin{tabular}{|c|c|c|c|c|c|c|}
\hline Study: & Type & Location & Sender & Receiver & Sample & Participants \\
\hline This study & UG & LF & $\mathrm{R}$ & $\mathrm{R}$ & $\mathrm{K}$ & Rural villagers in Sierra Leone \\
\hline Binzel and Fehr & $\mathrm{T}$ & $\mathrm{LF}$ & $\mathrm{A}$ & $\mathrm{R}$ & $\mathrm{K}$ & Members informal housing areas in Cairo \\
\hline Ligon and Schechter (2012) & $\mathrm{D}$ & $\mathrm{LF}$ & $\mathrm{R}$ & $\mathrm{R}$ & $\mathrm{K}$ & Rural villagers in Paraguay \\
\hline Leider et al. (2009) & $\mathrm{D}$ & $\mathrm{LF}$ & $\mathrm{R}$ & $\mathrm{R}$ & $\mathrm{K}$ & Harvard University undergraduates \\
\hline Dufwenberg and Muren (2006) & $\mathrm{D}$ & $\mathrm{L}$ & $\mathrm{R}$ & $\mathrm{A}$ & $\mathrm{K}$ & Students at Stockholm University \\
\hline Burnham (2003) & $\mathrm{D}$ & $\mathrm{L}$ & $\mathrm{R}$ & $\mathrm{R}$ & $\mathrm{U}$ & Subjects recruited via University of Arizona \\
\hline Bohnet and Frey (1999) & $\mathrm{D}$ & $\mathrm{L}$ & $\mathrm{R}$ & $\mathrm{R}$ & $\mathrm{U}$ & Economics students at the University of Zurich \\
\hline
\end{tabular}

Table 2: Overview Local Context in Experimental Games. Under 'Type', "UG", "T" and "D" indicate ultimatum, trust and dictator games, respectively. Under 'Location', "L" indicates laboratory games, whereas "LF" are lab-in-the-field experiments. Under 'Sender' and 'Receiver', "A" ("R") indicates whether the player is anonymous (revealed) towards the other player. Finally, the row 'Sample' indicates if the players are known to each other ("K"), or not ("U").

Several papers are close to our work; they either vary anonymity or use a subject pool that knows each other well. Table 2 presents six recent papers that use ultimatum, dictator or trust games to investigate the effects of varying the anonymity of players. Both Burnham (2003) and Bohnet and Frey (1999) conduct a set of dictator games where both senders and receivers are revealed to their counterparts. The first study finds that compared to the anonymous condition revealing the counterpart by means of a picture significantly increase the likelihood of giving exactly half of the endowment. The second study also finds a significant increase in donations as a result of relaxing the anonymity of both players - in this case the subjects were asked to stand up and look at each other in silence before they make their decision anonymously. In both studies, subjects are students that do not know each other outside of the game. Bohnet and Frey (1999), for example, explicitly notes that "The subjects were recruited during their second week at the university. Therefore most students did not know each other before the experiment (p.47)."

In contrast, Binzel and Fehr (2013) and Dufwenberg and Muren (2006) conduct, respectively, a set of trust and dictator games in which the participants explicitly do know each other. Participants in Binzel and Fehr (2013) are residents of an informal housing area in Cairo. Residents played the game twice: once with a friend and once with an anonymous individual. Their results show that trust is higher among friends than among strangers and that higher trust among friends is related to the principal's belief of trustworthiness.

of identifiability. Senders tend to give more to receivers that have been preselected as compared to ones that will be selected subsequent to the allocative decision. Importantly, these the experimental games are conducted with individuals that do not know each other. In the classic game the dictator contributes to somebody from a hypothetical group. In the local setting, however, interactions are always with identified individuals. However, these games measure altruism and not fairness, like the ultimatum game. 
Dufwenberg and Muren (2006) manipulate the degree of anonymity between subjects by varying the circumstances under which payouts are made: the sender would either pick up the payment in private or would have to come on stage during an auditorium lecture (the amount being announced, a few hundred people watching). Surprisingly, the authors find that less is given when the giver is paid on stage rather than in private. They argue that it is difficult to draw conclusions because as anonymity is manipulated it is likely that other motivationally relevant aspects change as well, introducing serious confounding factors. Both studies, however, only reveal one of the players.

Closest to our study are Leider et al. (2009) and Ligon and Schechter (2012). The first, conducted online dictator games among Harvard University undergraduates from the same dormitory and decomposes the motivation for sharing in (1) baseline altruism toward a randomly selected stranger, (2) directed altruism: sharing with friends rather than strangers, and (3) giving motivated by the prospect of future interaction (by revealing the sender). They find support for both mechanisms, although the future interaction effect is half as strong as the directed altruism effect. Ligon and Schechter (2012) conduct a set of dictator games with households in fifteen villages in rural Paraguay. Dictators were asked to play four games which varied whether or not the dictator was anonymous, and whether the recipient was randomly selected from the set of households in the village or was purposefully selected by the dictator. They decompose the motivation for sharing and estimate the relative importance of baseline sharing (the classic game), directed altruism (where the dictator chooses the receiver), sanctions (the dictator is revealed), and reciprocity (the dictator chooses the receiver and the dictator is revealed). The authors find that although baseline sharing (Anonymous $\rightarrow$ Random) is high, activating the three motives induces an increase in donation when moving from the AnonymoustoRandom, AnonymoustoChosen, RevealedtoRandom, and RevealedtoChosen variation.

\subsection{The Ultimatum Game: Public and Private Norms of Fairness}

In the ultimatum game, a sender $S$ selects the division of an initial endowment, promising a proportion $x$ to the receiver, $T$. If the receiver accepts the proposal, then $S$ receives $1-x$ and $T$ receives $x$. If $T$ rejects the proposal, both $S$ and $T$ receive 0 .

Throughout this subsection, we will assume that $S$ behaves rationally, given $T$ 's beliefs about fairness. This has two major implications for the analysis. First, $T$ behaves according to notions of fairness, and not necessarily financial gain. As such, $T$ may reject a proposal where she is offered some $x>0$ if it is not a high enough fraction. Second, this assumes that $S$ offers the lowest fraction $x$ that $T$ is willing to accept. Note that $S$ may still be altruistic. Consider a dictator game where $S$ offers $z$ to $T$, and does not require $T$ 's approval as in the ultimatum game. If $z>0$, then we would say that $S$ shows altruism. 
The rationality assumption only implies that $T$ would reject an offer of $z$ in the ultimatum game (and thus $S$ must offer $x>z$ ). This rationality assumption is corroborated by the very low rejection rate in proposals in the game.

We assume that each individual $i$ in the population is fully characterized, in behavior and reputation, by a vector of relevant attributes, $\mathbf{a}_{i}$. The act of revealing an individual in the ultimatum game corresponds to giving information to all players about the attribute vector of the individual. When the individual is not revealed, we will denote the corresponding attribute vector as $\overline{\mathbf{a}}$.

For a sender, $S$ and receiver $T, S$ selects an action $x$ based upon her own attributes and those of $T$. If $T$ is not revealed, then she makes the decision based upon her own attributes and $\overline{\mathbf{a}}$ for the receiver. Now let $u_{T}$ be the perceived (from $S$ ) utility function for $T$ increasing in the offer. The utility function is perceived because in an ultimatum game the sender rarely fully knows the utility function of the receivers (although she may have a good idea in a local context). This explains why some variation in offers will exist even in the classic ultimatum game $:^{3}$ The perceived utility function for $T$ is also a function of whether the sender, reciever, or both, have been revealed, since this affects the receivers notions of fairness. Thus, the perceived utility function for $T$ can be written as $u_{T}\left(x, \alpha_{S}, \alpha_{T}\right)$, where $\alpha_{S}=\mathbf{a}_{S}$ if $S$ has been revealed and $\overline{\mathbf{a}}$ otherwise.

$S$ perceives that $T$ will accept the offer if $u_{T}\left(x, \alpha_{S}, \alpha_{T}\right) \geq u_{T}\left(0, \alpha_{S}, \alpha_{T}\right)$. Since $S$ is rational, she always selects $x^{*}$ such that:

$$
u_{T}\left(x^{*}, \alpha_{S}, \alpha_{T}\right)=u_{T}\left(0, \alpha_{S}, \alpha_{T}\right)
$$

We analyze the implied equilibrium offer $x^{*}\left(\alpha_{S}, \alpha_{T}\right)$. To be concrete, $E\left(x^{*}(\overline{\mathbf{a}}, \overline{\mathbf{a}})\right)$ denotes the expected offer in the classic ultimatum game, $E\left(x^{*}\left(\overline{\mathbf{a}}, \mathbf{a}_{T}\right)\right)$ denotes the expected offer in the receiver-revealed ultimatum game, $E\left(x^{*}\left(\mathbf{a}_{S}, \overline{\mathbf{a}}\right)\right)$ denotes the expected offer in the sender-revealed game, and $E\left(x^{*}\left(\mathbf{a}_{S}, \mathbf{a}_{T}\right)\right)$ denote the expected offer when both are revealed. These serve as the parameters of interest in this study.

In the receiver-revealed game, we measure the perceived reputation effects of the receiver upon her beliefs about the norm of fairness. For instance, an elite individual such as the chief may believe that when his identity is revealed, he should receive a high offer as a sign of respect. Knowing this, the sender will offer a high amount. If $E\left(x^{*}\left(\overline{\mathbf{a}}, \mathbf{a}_{T}\right)\right)>E\left(x^{*}(\overline{\mathbf{a}}, \overline{\mathbf{a}})\right)$, then this implies that the average individual personally believes she has a superior reputation to average reference person in the population, reflecting a difference in perceptions and reality.

The sender-revealed game tests the reputation effects of the sender. For instance, a

\footnotetext{
${ }^{3}$ Although we do not explicitly model the perception as a function of the attributes of $S$ for clarity of exposition, it is relatively straightforward to do.
} 
particularly wealthy person may be expected to offer a higher percentage of her endowment. If $E\left(x^{*}\left(\mathbf{a}_{S}, \overline{\mathbf{a}}\right)\right)>E\left(x^{*}(\overline{\mathbf{a}}, \overline{\mathbf{a}})\right)$, the average perceived reputation of the other person is superior to the average reference person in the population. This is unlikely but plausible.

Finally, when both sender and receiver are revealed, $E\left(x^{*}\left(\mathbf{a}_{S}, \mathbf{a}_{T}\right)\right)$ tests the effect of interpersonal relations on norms of fairness. For instance, if two individual have a positive history they might be expected to offer more to each other, whereas if they have a negative history they would be expected to offer less. If $E\left(x^{*}\left(\mathbf{a}_{S}, \mathbf{a}_{T}\right)\right)>E\left(x^{*}(\overline{\mathbf{a}}, \overline{\mathbf{a}})\right)$, then interpersonal relations are on average positive. We also expect there to be a greater variation in offers in this version of the game due to the presence of both positive and negative interpersonal relations.

\section{Experimental Design}

We conducted our study in 35 small and remote communities in rural Sierra Leone where interactions are predominantly local. Behavior and social interactions are governed by a deeply entrenched patronage relationship of interrelated gifts and obligations. The reach of government is limited, and formal legal and political institutions are less important than the informal social structures. Local elites, often appointed for life, have great authority to organize economic and social activity, including the power to raise taxes, mobilize labor, settle disputes and allocate resources such as land, labor and reproductive opportunities (Richards, 1990; Acemoglu et al., 2013; Mokuwa et al., 2011) 4 Community-level activities such as the organization of public goods projects, dispute settlement and collaborative efforts are governed by local institutions and social norms of cooperation (Sawyer (2008), Fanthorpe and Maconachie (2010), Glennerster et al. (2012)).

We invited 632 randomly sampled households in 35 communities to participate in one of four versions of the ultimatum game. We grouped the participants into 316 randomly created dyads. We then randomly assigned each individual in the dyad to the role of sender or receiver, stratified by village. The senders were endowed with 5,000 Le (around 1.1 USD, about a days wage for unskilled labor) and asked to share with the receiver. Upon receiving the offer the receiver could accept or reject the offer. If accepted, the sender and receiver kept the division proposed by the sender, otherwise both received nothing.

To contrast individual behavior in the classic game with that at the local level we randomly allocated the dyads to one of four versions. The first is the classic dictator game (AA), where both the sender and the receiver play anonymously. In a second version (AR) we reveal the identity of the receiver to the sender. Sender contributions are influenced

\footnotetext{
${ }^{4}$ It is argued that the exclusionary nature of these relationship was an important contributing factor for the 1991-2002 civil war (e.g. Richards (2005), Fanthorpe (2001), Mokuwa et al. (2011)).
} 
by the knowledge of the receiver's attributes (Factor 2), the structure of the network connection between the individuals (Factor 3), and the fact that the sender plays with an identified individual (Factor 4). In a third version (RA) the sender is identified to the receiver, and the sender makes her decision knowing that the receiver will know her name. In this setting sender contributions are influenced by concerns about future reciprocity (Factor 1). Finally, to mimic the local context, a fourth version (RR) reveals both the receiver to the sender and the sender to the receiver, activating all four factors.

Using exit surveys we collected additional data on participant characteristics (age, gender, education, etc.) for both the sender and the receiver. We asked a set of questions to assess the social connectedness of dyad partners, including information on kinship ties, cooperation in farming, sharing of consumption and risk, and the financial links between participants. Receiver characteristics should affect sender behavior in the AR and RR conditions. Sender characteristics should affect receiver behavior in the RA and RR conditions 5 Dyad characteristics should matter in the AR, RA, and RR conditions.

Our main identification strategy is straightforward. We compare the average offers across the four versions, where we cluster our standard errors at the village level. Moreover, by making use of the data collected in the follow up surveys, will also investigate whether there are important sources of heterogeneity in contributions based upon sender, receiver and dyad characteristics.

\section{Results}

Table 4 summarizes some individual characteristics of our subjects. Our players are on average 44 years old, lived in the village for over 18 years and predominantly male, Muslim, and ethnically Mende. Mean family size is 6 and half the village has chiefly blood. Our main experimental data is summarized in Figure 1 which shows the frequency distributions for each of the four game variations. In total, $99 \%$ of the senders made a positive offer, with only three donating zero. The average offer is $37 \%$, or 1840 Le. In total, 8 of the 316 offers were rejected (average offer in that case was 1438 Le). These results are in line with a large literature in economics and political science that typically finds the majority of offers in the range of 25-50\% of the endowment, with few offers below $5 \%$ and responder frequently reject offers below $20 \%$ of fixed amount (Levitt and List (2007)).

Table 3 shows the average sender offer by variation, and illustrates the paper's main contribution. Each cell on the diagonal reports the average contribution by variation. Randomization inference p-values are reported in parentheses ${ }^{6}$ The off-diagonal cells test the

\footnotetext{
${ }^{5}$ As we will see in the next section, all but $2 \%$ of the receivers accepted the sender's proposed distribution.

${ }^{6}$ The p-values are based on randomization inference (Fisher, 1935) based on 10,000 simulations.
} 


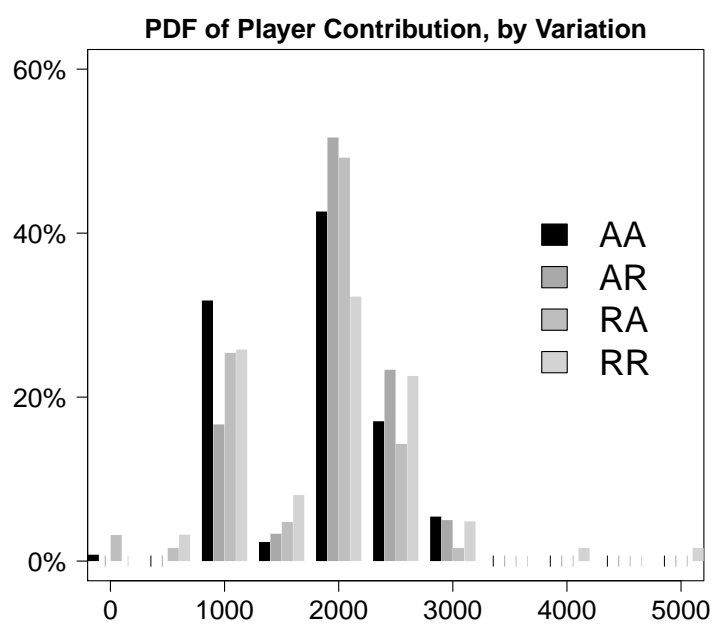

Figure 1: Left panel shows the distributions of contribution by variation. Data is based on a total of 314 senders: 129 (AA), 60 (AR), 63 (RA) and 62 (RR).

differences across game variations. Offers are highest in the revealed receiver (AR) condition. Compared to the classic game (AA), revealing the receiver leads to an almost $11 \%$ increase in offers. This can be explained by the personal relationship between sender and receiver (Factor 2), the social connectedness of the dyad (Factor 3), or the identified victim effect (Factor 4). A similar significant difference in behavior is found when comparing the RA condition to the RR condition. Again, the one thing that varies between conditions is that the sender learns who the receiver is in the RR condition. And again, this information leads to a large increase in offer size (an 10\% increase). These findings are consistent with positive in-group bias. Participants in this study are from small, rural villages where livelihoods and social structures are highly interdependent. Naming an individual makes salient that personal relationship. We take the fact that revealing the identity of the receiver leads to higher offers as evidence that social relationships in these villages are generally positive.

Average offers are lowest in the condition in which the sender is revealed to the receiver (RA). Participants offer on average $34 \%$ of their endowment, which is not statistically distinguishable from offers in the classic game AA (36\%). When a sender does not know who her counterpart is, but knows that her counterpart will know her name, the sender sends essentially the same amount as when she is making offers anonymously. In fact, RA offers are slightly lower than AA offers, and RR offers are slightly lower than AR, although neither difference is statistically significant in a two-sided test. Players in the experiment seem to be fairly unaffected by the knowledge that their counterpart oberves their allocative decision. This contradicts experimental evidence that being watched leads to more pro-social behavior (see Levitt and List (2007)). This indicates people in these 


\begin{tabular}{c|cccc} 
& AA & AR & RA & RR \\
\hline AA & $1794.57^{* * *}$ & $188.75^{* *}$ & -72.35 & 103.81 \\
& $(0.00)$ & $(0.01)$ & $(0.33)$ & $(0.18)$ \\
AR & & $1983.33^{* * *}$ & $-261.11^{* * *}$ & -84.94 \\
& & $(0.00)$ & $(0.00)$ & $(0.28)$ \\
RA & & & $1722.22^{* * *}$ & $176.16^{* *}$ \\
& & & $(0.00)$ & $(0.02)$ \\
RR & & & & $1898.38^{* * *}$ \\
& & & & $(0.00)$ \\
\hline
\end{tabular}

\begin{tabular}{cccc} 
AA & AR & RA & RR \\
\hline $642.29^{* * *}$ & -105.78 & -2.38 & $173.21^{* * *}$ \\
$(0.00)$ & $(0.12)$ & $(0.99)$ & $(0.02)$ \\
& $536.51^{* * *}$ & 103.40 & $278.99^{* * *}$ \\
& $(0.00)$ & $(0.17)$ & $(0.00)$ \\
& & $639.92^{* * *}$ & $175.59^{*}$ \\
& & $(0.00)$ & $(0.06)$ \\
& & & $815.51^{* * *}$ \\
& & & $(0.00)$ \\
\hline
\end{tabular}

Table 3: Contributions by Game Variation. Left table reports mean donations, p-values, based on randomization inference, in parentheses. Right table reports standard deviations, p-values, based on an F-test to compare the variances of two samples, in parentheses. $* p \leq 0.10, * * p \leq 0.05, * * * p \leq 0.01$.

locally connected settings seem to exhibit the same level of fairness whether or not their actions are observed by a co-villager. It may be evidence that there is a certain norm for giving and everyone follows it, whether or not someone will know. These villages are characterized by strong norms governing other economic activity such as sharing harvests, swapping labor, and providing local governance.

We have also examined the variance of offers across the four versions of the game. Table 3 shows the standard deviation of offers across the four variants. Standard deviation of the offers decline when moving from AA to AR. As expected, there is, a large increase in the standard deviation of offers in the $R R$ version compared to the other three versions. The standard deviation of offers under $\mathrm{RR}$ is more than double that of any other version (significance levels are always below 0.06 when compared to the standard deviation of AA, $\mathrm{AR}$, and RA versions).

\subsection{Heterogeneous Treatment Effects}

In order to more fully understand the differences in variance across variations of the game, we also explore the explanatory power of player and dyad characteristics. This allows us to test the hypothesis that aside from average treatment effects, there may be heterogeneous effects of treatment conditions dependent on dyad and personal characteristics. Table 4 contains these results.

Table 4 presents evidence on the effect of a sender and receiver age, gender and position in the household on offers made under our four conditions. In addition, we investigate the importance of both players in a dyad being male, or members of the same family. Because subjects only played one version of the game we cannot investigate within-subject differences. We do not report estimated coefficients on receiver or dyad characteristics in the AA and the RA conditions because it is theoretically impossible that they have an 


\begin{tabular}{|c|c|c|c|c|c|c|c|c|}
\hline & AA & $\mathrm{AR}$ & $\mathrm{AR}$ & $\mathrm{AR}$ & RA & $\mathrm{RR}$ & $\mathrm{RR}$ & $\mathrm{RR}$ \\
\hline \multicolumn{9}{|l|}{ Sender characteristics } \\
\hline Household head & $\begin{array}{c}0.46 \\
(0.72)\end{array}$ & $\begin{array}{l}-0.58 \\
(0.71)\end{array}$ & $\begin{array}{l}-0.68 \\
(0.96)\end{array}$ & $\begin{array}{c}-0.5 \\
(1.04)\end{array}$ & $\begin{array}{c}1.21 \\
(0.91)\end{array}$ & $\begin{array}{l}-1.14 \\
(0.96)\end{array}$ & $\begin{array}{l}-0.01 \\
(0.92)\end{array}$ & $\begin{array}{l}-0.03 \\
(0.94)\end{array}$ \\
\hline Age & $\begin{array}{l}-0.01 \\
(0.01)\end{array}$ & $\begin{array}{l}-0.01 \\
(0.01)\end{array}$ & $\begin{array}{c}0 \\
(0.01)\end{array}$ & $\begin{array}{c}0.01 \\
(0.01)\end{array}$ & $\begin{array}{c}0 \\
(0.02)\end{array}$ & $\begin{array}{l}-0.02 \\
(0.02)\end{array}$ & $\begin{array}{l}-0.02 \\
(0.02)\end{array}$ & $\begin{array}{l}-0.02 \\
(0.02)\end{array}$ \\
\hline Male & $\begin{array}{c}0.89^{* *} \\
(0.38)\end{array}$ & $\begin{array}{c}1.22 \\
(0.76)\end{array}$ & $\begin{array}{c}1.13 \\
(0.96)\end{array}$ & $\begin{array}{c}0.41 \\
(1.57)\end{array}$ & $\begin{array}{l}-0.72 \\
(1.01)\end{array}$ & $\begin{array}{c}1.56^{* *} \\
(0.64)\end{array}$ & $\begin{array}{c}1.10^{* *} \\
(0.47)\end{array}$ & $\begin{array}{l}1.76^{*} \\
(1.07)\end{array}$ \\
\hline \multicolumn{9}{|l|}{ Receiver characteristics } \\
\hline Household head & & & $\begin{array}{c}1.28 \\
(0.87)\end{array}$ & $\begin{array}{c}1.78^{* *} \\
(0.75)\end{array}$ & & & $\begin{array}{c}-1.98^{*} \\
(1.11)\end{array}$ & $\begin{array}{c}-2.13^{*} \\
(1.20)\end{array}$ \\
\hline Age & & & $\begin{array}{c}0 \\
(0.02)\end{array}$ & $\begin{array}{c}0 \\
(0.02)\end{array}$ & & & $\begin{array}{c}0.02 \\
(0.02)\end{array}$ & $\begin{array}{c}0.02 \\
(0.02)\end{array}$ \\
\hline Male & & & $\begin{array}{l}-0.33 \\
(0.67)\end{array}$ & $\begin{array}{l}-0.98 \\
(1.40)\end{array}$ & & & $\begin{array}{c}0.71 \\
(0.74)\end{array}$ & $\begin{array}{c}1.48 \\
(1.64)\end{array}$ \\
\hline \multicolumn{9}{|l|}{ Dyad characteristics } \\
\hline Family & & & & $\begin{array}{c}2.37 \\
(1.55)\end{array}$ & & & & $\begin{array}{c}0.43 \\
(0.69)\end{array}$ \\
\hline Both Male & & & & $\begin{array}{c}0.9 \\
(1.47)\end{array}$ & & & & $\begin{array}{l}-0.74 \\
(1.25)\end{array}$ \\
\hline $\mathrm{N}$ & 128 & 59 & 55 & 55 & 62 & 61 & 57 & 57 \\
\hline
\end{tabular}

Table 4: Results by variation. Results based on an ordered logit specification, with standard errors clustered at the village level. $* p \leq 0.10, * * p \leq 0.05, * * * p \leq 0.01$.

effect and the data confirms that to be the case.

Males offer significantly more money than females in the AA and the RR conditions, although the effect size is small. If the receiver is a head of a household, in the AR version senders tend to offer significantly, but in the RR condition they send significantly less. This reversal is unexpected, but provides evidence of some theoretical mechanism that mitigates altruism. There may be a norm to respect other heads of households by making them gifts when possible (explaining the AR result). At the same time, giving a gift to another head of household may be insulting to that head of household, who may not want to be seen to be in need of charity. Alternatively, perhaps offers are low when the sender is revealed because the sender knows that he or she may develop a reputation for giving, and others in the village will take advantage of them by asking for more handouts. Both these mechanisms could explain the $\mathrm{RR}$ result of lower offers. More research is needed to understand this phenomenon.

\section{Conclusion}

We argue that the classic ultimatum game abstracts from important drivers of human behavior. These drivers are important if we want to generalize lessons from the lab to the 
real world. In classic games subjects are drawn from a population of strangers, and play is anonymous. In contrast, when played locally, reciprocity, knowledge of relevant attributes, and the position within social networks may affect behavior.

This study was motivated by the recognition that most social interaction takes place among individuals that know each other well and have regular interaction. This is particularly the case in developing societies-most farmers sell all their crops to middlemen from their village, women obtain the majority of their health care from local midwifes, villages rely on the local imam to educate their children, and families turn to neighbors to for loans, assistance, etc.

We implement a series of ultimatum game in highly connected, rural villages in Sierra Leone. Subjects are randomly assigned either the classic game or a modified version, where either sender, receiver or both are revealed to their counterpart. Our main finding is that revealing the identity of the receiver has a significant positive effect on offers. This finding is robust and holds regardless of whether the sender too is revealed. This is consistent with other studies that reveal a receiver's identity in an ultimatum game with socially unconnected subjects. This suggests that personal beliefs about reputation exceed that of the status quo; that is, the average person believes she deserves a larger fraction of the pie than the status quo.

Our second finding is that revealing the sender's identity to the receiver has no significant effect on offers, and if anything leads to marginally lower offers. This effect is robust to whether or not the receiver is identified. This suggests that the average reputation in terms of the level of fairness of other individuals is nearly identical to beliefs about the level of fairness of the status quo.

Third, we find that the variance in the size of the offers is highest in the fully local version of the game. This follows if reciprocity, knowledge of attributes, and social connections are be both positive and negative. When those behavioral drivers are activated, we would expect to see a wider dispersion of offers based upon whether previous interpersonal relations were good or bad.

Finally, we find evidence of some limited heterogeneous treatment effects. Males offer more than women as senders, senders offer substantially more if the receiver is revealed to be a family member, and senders tend to offer more to other household heads if senders are anonymous, but less if senders are revealed to receivers. This reinforces our interpretation that revealing the sender has little overall effect. Subjects seem to want to help their fellow heads of families in the village, but only if they can do so anonymously.

These results support our interest in incorporating context into any lab-in-the-field experiment, particularly in developing countries. The relative importance of basic individual preferences versus socially determined preferences, and the necessary conditions for indi- 
vidual preference to swamp or be swamped by social considerations, is a poorly developed area of research in experimental economics. This paper develops one approach to teasing out this relative importance, and highlights mechanisms for further study. 


\section{Online Appendix A: Balance Test}

The analysis in this paper relies on randomization which guarantees that the groups of individuals for each of the four variations are similar in expectation. In practice, however, it is possible for these units to differ simply by virtue of unlucky draws. To test this, we separated out by sender and receiver: age, gender, number of household members, potential for a member of the household to become a village chief, years the household has lived in the village, ethnicity, and religon. Table 5 lists the average for each variable for the four different variations, and the difference between them. While some differences are significant, there are no strong systematic differences across these four groups.

\begin{tabular}{lcccc|cccccc} 
Variable & AA & AR & RA & RR & AA-AR & AA-RA & AA-RR & AR-RA & AR-RR & RA-RA \\
\hline \hline Sender & & & & & & & & & & \\
\hline Age & 43.06 & 44.87 & 44.46 & 37.53 & -1.80 & -1.40 & $5.53^{* *}$ & 0.41 & $7.33^{* *}$ & $6.93^{* *}$ \\
Male & 0.86 & 0.78 & 0.78 & 0.77 & 0.08 & 0.08 & 0.09 & 0.00 & 0.01 & 0.00 \\
Household members & 5.97 & 5.93 & 5.90 & 5.79 & 0.03 & 0.06 & 0.18 & 0.03 & 0.15 & 0.12 \\
Potential chief & 0.45 & 0.46 & 0.42 & 0.48 & -0.01 & 0.03 & -0.04 & 0.04 & -0.03 & -0.07 \\
Years in village & 17.13 & 19.40 & 20.91 & 15.53 & -2.28 & -3.79 & 1.6 & -1.51 & $3.88^{*}$ & 5.39 \\
Mende & 0.84 & 0.90 & 0.90 & 0.94 & -0.06 & -0.07 & $-0.10^{* *}$ & 0.00 & -0.04 & -0.03 \\
Muslim & 0.94 & 0.97 & 0.95 & 1.00 & -0.03 & -0.01 & $-0.06^{* *}$ & 0.01 & -0.03 & -0.05 \\
\hline Receiver & & & & & & & & & & \\
\hline Age & 41.31 & 45.69 & 44.87 & 45.54 & $-4.39^{* *}$ & -3.56 & $-4.23^{*}$ & 0.82 & 0.15 & -0.67 \\
Male & 0.79 & 0.86 & 0.89 & 0.83 & -0.07 & -0.10 & -0.03 & -0.02 & 0.04 & 0.06 \\
Household members & 5.49 & 6.44 & 6.70 & 5.78 & -0.95 & -1.21 & -0.29 & -0.27 & 0.66 & 0.93 \\
Potential chief & 0.34 & 0.51 & 0.53 & 0.39 & -0.17 & $-0.19^{* *}$ & -0.05 & -0.02 & 0.11 & 0.14 \\
Years in village & 20.45 & 16.88 & 23.18 & 20.07 & 3.57 & -2.73 & 0.39 & $-6.30^{* *}$ & -3.19 & 3.11 \\
Mende & 0.92 & 0.82 & 0.93 & 0.81 & 0.10 & -0.01 & 0.11 & $-0.11^{*}$ & 0.01 & $0.12^{* *}$ \\
Muslim & 0.96 & 0.96 & 0.98 & 0.92 & 0.00 & -0.02 & 0.04 & -0.02 & 0.04 & 0.06 \\
\hline \hline
\end{tabular}

Table 5: Balance Test. Standard errors clustered at the village level. $* p \leq 0.10, * * p \leq$ $0.05, * * * p \leq 0.01$. 


\section{References}

Acemoglu, D., Chaves, I. N., Osafo-Kwaako, P., and Robinson, J. A. (2013). Indirect Rule and State Weakness in Africa: Sierra Leone in Comparative Perspective. Working paper.

Binzel, C. and Fehr, D. (2013). Social Distance and Trust: Experimental Evidence from a Slum in Cairo. Journal of Development Economics, 103:99-106.

Bohnet, I. and Frey, B. S. (1999). The Sound of Silence in Prisoner's Dilemma and Dictator Games. Journal of Economic Behavior $\&$ Organization, 38(1):43-57.

Bornstein, G. and Yaniv, I. (1998). Individual and Group Behavior in the Ultimatum Game: Are Groups More "Rational" Players? Experimental Economics, (1):101-108.

Bowles, S. and Gintis, H. (2004). The Evolution of Strong Reciprocity: Cooperation in Heterogeneous Populations. Theoretical Population Biology, 65(1):17-28.

Burnham, T. C. (2003). Engineering Altruism: A Theoretical and Experimental Investigation of Anonymity and Gift Giving. Journal of Economic Behavior 85 Organization, $50(1): 133-144$.

Camerer, C. F. (2003). Behavioral Game Theory: Experiments on Strategic Interaction. Princeton University Press, Princeton.

Cameron, L. A. (1999). Raising the Stakes in the Ultimatum Game: Experimental Evidence From Indonesia. Economic Inquiry, 37(1):47-59.

Charness, G. and Gneezy, U. (2008). What's in a Name? Anonymity and Social Distance in Dictator and Ultimatum Games. Journal of Economic Behavior 83 Organization, $68(1): 29-35$.

Dufwenberg, M. and Muren, A. (2006). Generosity, Anonymity, Gender. Journal of Economic Behavior \& Organization, 61(1):42-49.

Fafchamps, M. and Lund, S. (2003). Risk-sharing Networks in Rural Philippines. Journal of Development Economics, 71(2):261-287.

Fanthorpe, R. (2001). Neither Citizen nor Subject? 'Lumpen' Agency and the Legacy of Native Administration in Sierra Leone. African Affairs, 100(400):363-386.

Fanthorpe, R. and Maconachie, R. (2010). Beyond the 'Crisis of Youth'? Mining, Farming, and Civil Society in Post-War Sierra Leone. African Affairs, 109(435):251-272.

Fisher, R. A. (1935). The Design of Experiments. Oliver and Boyd, London. 
Gale, J., Binmore, K. G., and Samuelson, L. (1995). Learning To Be Imperfect: The Ultimatum Game. Games and Economic Behavior, 8:18-20.

Glennerster, R., Miguel, E., and Rothenberg, A. (2012). Collective Action in Diverse Sierra Leone Communities. Working paper.

Güth, W., Huck, S., and Müller, W. (2001). The Relevance of Equal Splits in Ultimatum Games. Games and Economic Behavior, 37(1):161-169.

Guth, W., Schmittberger, R., and Schwarze, B. (1982). An Experimental Analysis of Ultimatum Bargaining. Journal of Economic Behavior \& Organization, 3:366-388.

Habyarimana, J., Humphreys, M., Posner, D. N., and Weinstein, J. M. (2007). Why Does Ethnic Diversity Undermine Public Goods Provision? American Political Science Review, 101(4):709-725.

Hamilton, D. L. and Sherman, S. J. (1996). Perceiving Persons and Groups. Psychological Review, 103(2):336-55.

Hoffman, E., Mccabe, K. A., and Smith, V. L. (1996). On Expectations and the Monetary Stakes in Ultimatum Games. International Journal of Game Theory, 25:289-301.

Holm, H. J. (2000). Gender-Based Focal Points. Games and Economic Behavior, 32(2):292314.

Jackson, M. O. (2008). Social and Economic Networks. Princeton University Press.

Jenni, K. E. and Lowenstein, G. (1997). Explaining the "Identifiable Victim Effect". Journal of Risk and Uncertainty, 14:235-257.

Kagel, J. H., Kim, C., and Moser, D. (1996). Fairness in Ultimatum Games with Asymmetric Information and Asymmetric Payoffs. Games and Economic Behavior, 13(1):100-110.

Kahneman, D., Knetsch, J. L., and Thaler, R. (1986). Fairness as a Constraint on Profit Seeking: Entitlements in the Market. American Economic Review, 76(4):728-741.

Kogut, T. and Ritov, I. (2005). The "Identified Victim" Effect: An Identified Group, or Just a Single Individual? Journal of Behavioral Decision Making, 18(3):157-167.

Leider, S., Mobius, M. M., and Do, Q.-A. (2009). Directed Altruism and Enforced Reciprocity in Social Networks. Quarterly Journal of Economics, pages 1815-1851.

Leimar, O. and Hammerstein, P. (2001). Evolution of Cooperation Through Indirect Reciprocity. Proceedings of the Royal Society B: Biological Sciences, 268(1468):745-53. 
Levitt, S. D. and List, J. A. (2007). What Do Laboratory Experiments Measuring Social Preferences Reveal About the Real World? The Journal of Economic Perspectives, $21(2): 153-174$.

Ligon, E. and Schechter, L. (2012). Motives for Sharing in Social Networks. Journal of Development Economics, 99(1):13-26.

Mokuwa, E., Voors, M., Bulte, E., and Richards, P. (2011). Peasant Grievance and Insurgency in Sierra Leone: Judicial Serfdom as a Driver of Conflict. African Affairs, 110(440):339-366.

Oosterbeek, H., Sloof, R., and van de Kuilen, G. (2004). Cultural Differences in Ultimatum Game Experiments: Evidence from a Meta-Analysis. Experimental Economics, 7(2):171188.

Richards, P. (1990). Local Strategies for Coping with Hunger: Central Sierra Leone and Northern Nigeria Compared. African Affairs, 89(355):265-275.

Richards, P. (2005). To Fight or to Farm? Agrarian Dimensions of the Mano River Conflicts (Liberia and Sierra Leone). African Affairs, 104(417):571-590.

Roth, A. E. (1995). Bargaining Experiments. In The Handbook of Experimental Economics, pages 253-342.

Ruffle, B. J. (1998). More Is Better, But Fair Is Fair: Tipping in Dictator and Ultimatum Games. Games and Economic Behavior, 23(2):247-265.

Sawyer, E. (2008). Remove or Reform? a Case for (Restructuring) Chiefdom Governance in Post-Conflict Sierra Leone. African Affairs, 107(428):387-403.

Small, D. A. (2003). Helping a Victim or Helping the Victim: Altruism and Identifiability. Journal of Risk and Uncertainty, 26:5-16.

Solnick, S. J. (2001). Gender Differences in the Ultimatum Game. Economic Inquiry, $39(2): 189-200$.

Solnick, S. J. and Schweitzer, M. E. (1999). The Influence of Physical Attractiveness and Gender on Ultimatum Game Decisions. Organizational behavior and human decision processes, 79(3):199-215.

Thaler, R. H. (1988). Anomalies The Ultimatum Game. Anomalies: The Ultimatum Game, 2(4):195-206. 
Trivers, R. L. (1971). The Evolution of Reciprocal Altruism. Quarterly Review of Biology, $46(1): 35-57$.

Udry, C. (1994). Risk and Insurance in a Rural Credit Market: An Empirical Investigation in Northern Nigeria. Review of Economic Studies, 61(3):495-526. 